young pupil. It is, I take it, by a girl, though your article says a boy. But is there much real value in the exercise even when such clearness is attained?

I make it a conscientious matter from the first to answer all child questions about nature in a truthful manner. They are never put off with false theories involving supernatural or other agencies. For instance, what child fails by three to five years of age to ask how do the stars stay up there? How easy to put him off with some farcical or miraculous supposition. On the contrary, the simplest possible attempt should be made to give him the real explanation. Will he understand it? If not entirely, he will be on the right road. There will not be something to undo by and by. Why can be not understand attraction as well as you or I ? Only he must have it explained by what he is familiar with.

We are getting on the right track. Science furnishes studies infused with romance. No novel has the fascination for young people of a well-told geology or biology. E. P. POWELL.

\section{The care of pamphlets.}

Every scientific library, public or private, contains pamphlets by the thousand, and nothing is more necessary for the accommodation of those who use it than some available system of binding which shall preserve from destruction and at the same time be accessory to a convenient system of classification.

Some system of permanent individual bindings is needed which shall afford $1^{\circ}$. permanent protection $2^{\circ}$. the possibility of a perfect classification, and the intercalation of new material from day to day ; $3^{\circ}$. opportunity for perfect labelling and cataloguing; $4^{\circ}$. the greatest convenience to the reader. The best endowed public libraries can perhaps afford to pay a bookbinder to put separate covers on pamphlets, and it is the practice of many of them thus to care for the most important. The cost is, however, very considerable. What the private individual needs is a binding-case much more inexpensive-one in which he can himself insert his pamphlets. Feeling sure that it was possible to meet this need, I undertook an investigation. The bookbinders, with their skilled workmen and their expensive binder's board, did not seem to be in a position to supply this demand. I found upon inquiry that the simplest form of binding-case cost from twelve to fifteen cents. I next turned to the paper-box manufacturers, who employ unskilled laborers, and who use less expensive materials. I found that binders for octavo pamphlets, when ordered in considerable quantities, could be made for $\$ 4.50$ a hundred, and quarto binders for $\$ 7.50$ a hundred. These binders are made with sides of thick paper-pulp board, which is not likely to warp, and with backs of binder's muslin, and are covered with binder's paper. They have muslin stubs, upon which the pamphlets may be glued, and may be made of varying thickness. The most useful sizes will doubtless be one-eighth, onequarter, one-half, three-quarters and one inch. The sizes I use are, octavo, $63-4 \times 10$ inches; quarto, $10 \times 12$ inches. The octavo covers are made larger than the ordinary octavo page, to include papers in imperial octavo; duodecimo pamphlets may also be put in these covers, for the sake of uniformity, and convenience in classification. Each binder has a blank label on one of its upper corners, upon which the name of its contents are written. I arrange these in paper boxes, upon ordinary book shelves, so placed that the contents of each box may be handled in the same manner as the cards in a card catalogue, the position of the title labels facilitating this operation. A system of deep drawers would be equally convenient.

I also use these pamphlet-cases for filing letters, photographs, newspaper clippings and other literary material. A stout manilla envelope being glued to the stub with its opening to the right, and next to the back, is covered and protected by the sides of the binder, and may be filled with loose papers, their character being indicated upon the label outside. The binder may then be arranged with the pamphlets or elsewhere. Classified scrap-books may very easily be made by fastening a few sheets of book paper to the stubs, and bundles of letters may be bound in in a similar manner. I have for years used binding-covers of a still cheaper and simpler form, which are simply sheets, 9 1-2x13, made of the stout, thick paper used in herbaria for genus covers. These are fastened to the pamphlets by the use of the patent staple-like paper fasteners, sold by stationers. They are labelled and arranged in the same manner as the binders, as described above, and serve an excellent purpose, the paper, though less indestructible than is desirable, being very stiff and durable. It is simply waste of time to use even the thickest of ordinary manilla paper for this purpose.

This note is sent in the hope that it may draw forth descriptions of other methods of caring for pamphlets.

U. S. national museum, Washington.

\section{Color and other associations.}

In Science for the 18th of September, I was much interested in the letters on 'color and other associations,' for I have always experienced similar illusions. According to my fancy, the months have always appeared as below.

The days of the week are in the form of a circle, Sunday on top, Thursday below; the duys rotating from right to left. Sunday appears yellow, Monday pale straw, Tuesday green, Wednesday yellow, Thursday orange, Friday black, and Saturday whitish gray. The numbers arrange themselves as follows:

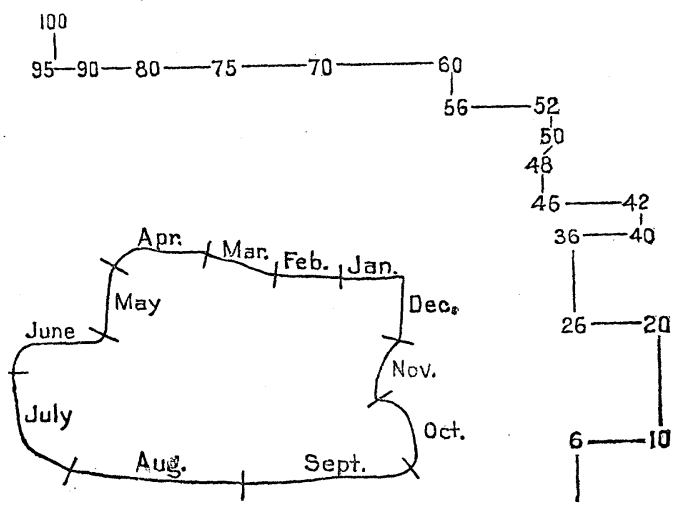

When I think of a number I always place it in the diagram. Above 100, the numbers go between the hundreds like the diagram, and the hundreds themselves follow a similar course. 
In committing prose or verse to memory, the positions of the paragraphs fix themselves in my mind so firmly that when I recite I almost read the words from the air before me. unless I have learned them by ear, in which case there is no illusion at all.

$$
\text { Bedford, N. Y., Sept. } 28 .
$$$$
\text { Thatcher T. P. Luquer. }
$$

The matter of forms in series of numbers, months and days seems of considerable philosophical interest. Is there not herein a hint that, although to broad features, the great principles of mental states and operations are every where the same, yet the minutiæ may be utterly incongruous and irreconcilable; and hence, that in the minute analysis of these things philosophers must always in a measure fail, because the assumption on which all philosophy is built, that minds act alike, proves to be not wholly reliable? What seems a necessity of thought, or at least a constant accompaniment of thought to one, seems ridiculous and unthinkable to another. Such forms have existed in my own mind from my earliest remembrance, yet I never thought of them as other than naturally common to all, till within a few years,

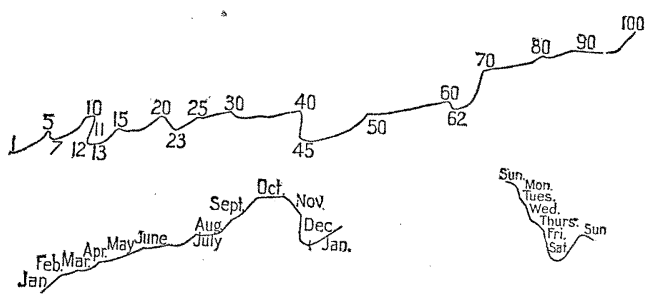

finding them entirely wanting to some minds. The annexed diagrams show that, while the numbers and the months take in general an ascending direction, the days of the week have a steep grade downwards to my mind.

Southbridge, Mass.

Some notes on color in Science recently recalled a study made by me when in Chicago a few years since. I was made president of the Kindergarten association when it was formed in 1875 . This gave me occasion for several very curious lines of inquiry. Only one of these will be appropriately recalled now. A casual remark of that able teacher, Mrs. Putnam, led me to ask her which gift the children under seven first chose. She answered yellow. I said, "What, in preference to red or blue!" "Yes," she repeated. " with" only one exception, invariably yellow." I then inquired of Miss Eddy, whose fine powers of observation were unequalled, and her answer was yellow. I cculd hardly believe it ; but from every teacher there; or elsewhere, I have received the same answer, a few adding that they have had in charge a few children who were exceptions. This tallies with my recollections of my own childhood, and is confirmed by others. If it be an established fact, which I will not aver, to what shall we attribute it? Is it improbable that there is an unconscious relation between the growing child and the ray most concerned in growth, as there seems to be between old age and the red ray? We certainly outgrow at an early age our preference for the yellow.

Clinton, N. Y.

\section{Ball of electric fire.}

Mr. J. V. WuRdeman says that a ball of fire, as large as a child's head, came into his room at Leavenworth, hopped across the floor like a soap bubble rolling on a carpeted floor, went out through the side of the house at the corner opposite to where first seen, with a sort of explosion, or rather puff, not nearly so loud as a pistol shot nor so sharp, and tore off the rain pipe of tin. It lonked like an electric brush, not brilliant nor like the electric spark. His son, a little child, was playing on the bed: his mother snatched up the boy and was half way down stairs before the ball disappeared. The ball seems to have been like the St. Elmo lights. which I have seen on a vessel's yard arm, in the Gulf of Mexico, a pale brush of light, spherical in form, like the brush issuing from a metallic point in the prime conductor of the frictional electric machine.

\section{C. Mergs}

\section{Voss-Holtz electrical machine.}

A few days ago I accidentally received a pamphlet on the theory of the Voss-Holtz electrical machine, by E. B. Benjamin, dealer in physical apparatus, New York City.

The article states that " no perfectly satisfactory explanation of all the phenomena manifested by this machine has yet been made public in this country," and then gives the theory that was published in Science, for June 20,1884 . In many places the sentences are the same, almost word for word, except that he has lettered the parts of the machine, and used the letters for the names of the parts.

Mr. Benjamin gives no credit either to Science or to the author, and further copyrights, by itself, the part of the pamphlet containing the theory, the date of the copyright being 1885 .

$$
\text { Louisville, Ky., Oct. } 2 .
$$

\section{H. W. EATON.}

\section{Carnivorous habits of the striped squirrel.}

As the carnivorous habits of the musk-rat and other rodents have been under discussion during the past year, I wish to record a rather remarkable instance, which came to my notice in New Hampshire, May 27, 1883, in case of the striped or ground squirrel, Tamias striatus (L) Baird.

The chipmunk is usually regarded as a harmless vegetarian, living chiefly, if not wholly, upon nuts, fruits, and the seeds of grain and various plants; but this is probably not the whole truth of the matter, at least in the following case, for an account of which I am indebted to the Rev. F. M. Gray, of Plymouth, N. H.

On the morning of the day in question, he was in the woods, and stopped to listen to some bird, when his attention was called to a white-footed or deer mouse (Hesperomys leucopus, (Raf.) LeC.), which ran hurriedly past, carrying something in its mouth.

Suddenly a chipmunk, which had watched proceedings from a stump near at hand, pounced down upon the mouse, caught up what she had carried in her mouth, but had dropped through fright, and returning to his stump began to devour it greedily.

The captured prey could now be seen to be a young mouse, which the squirrel ate as he would a nut or a piece of apple, in this case beginning with the head. 